Saudi Journal of Pathology and Microbiology

Abbreviated Key Title: Saudi J Pathol Microbiol

ISSN 2518-3362 (Print) IISSN 2518-3370 (Online)

Scholars Middle East Publishers, Dubai, United Arab Emirates

Journal homepage: http://scholarsmepub.com/sjpm/

Original Research Article

\title{
Detection of Biofilm Production and its Quantification in Candida Isolates in a Tertiary Care Hospital
}

\author{
Gyaneshwar Tiwari $^{1 *}$, Bibhabati Mishra ${ }^{1}$, Vinita Dogra ${ }^{1}$, Poonam sood Loomba ${ }^{1}$, D. R. Arora ${ }^{2}$ \\ ${ }^{1}$ Govind Ballabh Pant institute of Postgraduate Medical Education and Research (GIPMER) New Delhi 110002, India \\ ${ }^{2}$ SGT University, Gurgaon-Badli Road, Chandu, Budhera, Gurugram, Haryana 122505, India
}

DOI: 1 10.36348/SJPM.2019.v04i10.011 $\quad$ | Received: 20.10.2019| Accepted: 27.10.2019| Published: 30.10 .2019

*Corresponding author: Gyaneshwar Tiwari

\section{Abstract}

Introduction: Candida biofilms adversely impact the health of the patients with increasing frequency and severity of disease and with soaring economic sequel. Objective: Qualitative detection of biofilm production and its quantification was performed in Candida isolates from patients infected with health care associated infection (HCAI). Method: A total of 55 Candida isolates were included in the study. Biofilm production was estimated by Tube method (TM) and Tissue culture plate method (TCP). Further quantification of the biofilm produced was performed by XTT (2, 3-bis (2-methoxy4-nitro-5-sulfophenyl)-5-[(phenylamino) carbonyl]-2H-tetrazolium hydroxide) reduction Assay and Dry weight measurement method. Result: All Candida isolates were found to be biofilm producers by all three (TM, TCP and XTT) methods. Quantity of biofilm produced by C. albicans ranged between 2.3 to $9.1 \mathrm{mg} /$ disk. Among non-albicans Candida Candida tropicalis) it was between 2.2 to $7.3 \mathrm{mg} / \mathrm{disk}$ whereas non-albicans Candida (except $C$. tropicalis) weight of the biofilm was 2.0 to $7.1 \mathrm{mg} /$ disk. Conclusion: Dry weight (DW) is the actual quantity of biofilm produced. Candida albicans produced higher quantity of biofilm than non-albicans Candida in the study. It is also concluded that quantitative detection of biofilm is definitely help clinician in deciding modality of treatment.

Keywords: Biofilm, XTT, Dry weight, Candida albicans, non-albicans Candida.

Copyright @ 2019: This is an open-access article distributed under the terms of the Creative Commons Attribution license which permits unrestricted use, distribution, and reproduction in any medium for non-commercial use (NonCommercial, or CC-BY-NC) provided the original author and sources are credited.

\section{INTRODUCTION}

Candida species is one of the most frequently encountered opportunistic fungi that cause severe infection in humans because of its virulence factors. Biofilms have great significance in public health, because biofilm-associated Candida exhibit dramatically decreased susceptibility to antifungal agents. Candida biofilms adversely impact the health of the patients with increasing frequency and severity of disease and with soaring economic sequel. Fungal infections develop frequently in immune-compromised patients, particularly in patients with prolonged, severe neutropenic episodes and with indwelling medical devices [1]. In one of the earliest studies documenting the ability of Candida to form biofilms, Marrie and Costerton reported formation of Candida parapsilosis biofilms on vascular catheters [2]. Initial studies also reported that Candida biofilms formed on different surfaces including Hickman catheters [3], soft contact lenses, ureteral stents [4], and corneas [5]. Subsequent studies have demonstrated that Candida biofilms can form on a wide variety of indwelling medical devices including dentures, central venous catheters (CVCs), and urinary catheters. These biofilms exhibit decreased susceptibility to most antimicrobial agents, which contributes to the persistence of infection [6].

Various methods are available for the qualitative and quantitative detection of Candida biofilms. Some of the commonly used qualitative methods of biofilm detection methods are visual and spectrophotometric methods [7-9] (Congo Red Agar, Tube method and Micotitre plate method, whereas quantitative method includes biochemical assay, i.e., the 2,3-bis (2-methoxy-4-nitro-5-sulfophenyl)-5[(phenylamino)carbonyl]-2H-tetrazolium hydroxide (XTT) reduction assay and dry weight (DW) measurements [10].

\section{OBJECTIVE OF THE STUDY}

The study was conducted to quantify biofilm production of Candida spp. isolated from different clinical samples of admitted patients of GIPMER, New Delhi. 


\section{METHODS}

Various clinical samples received from patients as per merit of the case (admitted in ICUs and wards) were processed as per standard microbiological methods. These Candida isolates were identified by conventional methods, CHROM agar and VITEK II.

\section{Candida Biofilm Detection}

After identification of the isolates they were further processed for determination of biofilm production. For qualitative detection of Candida biofilm production methods used were visual (Tube Method) and spectrophotometric methods (Tissue Culture Plate Method) [7-9].

Quantification of Biofilm production by the Candida spp. was performed by XTT reduction assay and Dry weight (DW) measurement [10].
- Dry weight: DW measurements represent total biofilm mass, including fungal cells and extracellular matrix.

- Wet weight (WW): WW measurements represent the entire, hydrated mass of biofilm.

\section{RESULTS}

This prospective study was conducted in the department of microbiology; G. B. Pant Institute of Post Graduate Medical Education and Research (GIPMER), New Delhi over a period of one year. Total 55 Candida isolates from patients of hospital acquired infections (HAI) were included in the study.

Maximum number of Candida isolates were from urine (catheterized) $47(85 \%)$ followed by respiratory tract samples $02(3 \%)$, body fluids $02(4 \%)$, implants $02(4 \%)$, blood $01(2 \%)$ and tissue $01(2 \%)$.

Table-1: Distribution of Candida species in clinical samples

\begin{tabular}{|l|l|l|l|}
\hline Type of sample & No. of samples & C.albicans & non-albicans Candida \\
\hline Urine (Catheterized) & 47 & 12 & 35 \\
\hline Fluids & 02 & 01 & 01 \\
\hline Implants(valves) & 02 & 00 & 02 \\
\hline Blood & 01 & 00 & 01 \\
\hline Respiratory samples & 02 & 00 & 02 \\
\hline Tissues & 01 & 01 & 00 \\
\hline Total & 55 & 14 & 41 \\
\hline
\end{tabular}

Maximum numbers of Candida isolates were from urine sample (47), out of which 12 were C. albicans and 35 were non-albicans Candida.

\section{Detection of Candida biofilm}

Qualitative detection of biofilm production was performed by Tube method (TM) and tissue culture plate (TCP) method.

\section{Detection of Candida biofilm by TM}

Results of biofilm production detected by TM depicted in Table 2.

Table-2: Biofilm production by tube method

\begin{tabular}{|c|c|c|c|c|c|c|}
\hline & & \multicolumn{2}{|c|}{ Candida sp. } & \multirow[b]{2}{*}{ Total } & \multirow[b]{2}{*}{$\begin{array}{c}\text { Pearson Chi- } \\
\text { Square }\end{array}$} & \multirow[b]{2}{*}{ p-value } \\
\hline & $\begin{array}{l}\text { Grading of } \\
\text { biofilm }\end{array}$ & C. albicans & $\begin{array}{c}\text { non-albicans } \\
\text { Candida }\end{array}$ & & & \\
\hline \multirow{3}{*}{$\begin{array}{l}\text { Biofilm } \\
\text { production } \\
\text { by tube } \\
\text { method }\end{array}$} & $\mathrm{M}$ & 2 & 6 & 8 & 1.38 & 0.501 \\
\hline & $\mathrm{S}$ & 10 & 33 & 43 & & \\
\hline & $\mathrm{W}$ & 2 & 2 & 4 & & \\
\hline \multicolumn{2}{|l|}{ Total } & 14 & 41 & 55 & & \\
\hline
\end{tabular}

By Tube Method (TM) 55 (100\%) Candida isolates were detected as biofilm producers. Out of which, $43(78.2 \%)$ were strong, 8(14.5\%) were moderate and $04(7.3 \%)$ were weak biofilm producers.

Of the 14 Candida albicans, 10 (71.4\%) were strong biofilm producers and $2(14.3 \%)$ isolates each are moderate and weak biofilm producers whereas of the 41 isolates of non-Candida albicans 33 (80.5\%), 6 $(14.6 \%)$ and $2(4.9 \%)$ were strong, moderate and weak biofilm producers respectively.

\section{Biofilm production detected by TCP method}

Findings of detection of biofilm production in Candida isolates by TCP method are given in the Table 3. 
Table-3: Biofilm production by TCP method

\begin{tabular}{|c|c|c|c|c|c|c|}
\hline & & \multicolumn{2}{|c|}{ Candida sp. } & \multirow[t]{2}{*}{ Total } & \multirow{2}{*}{$\begin{array}{c}\text { Pearson } \\
\text { Chi-Square }\end{array}$} & \multirow[t]{2}{*}{ p-value } \\
\hline & $\begin{array}{l}\text { Grading of } \\
\text { biofilm }\end{array}$ & $\begin{array}{c}C . \\
\text { albicans }\end{array}$ & $\begin{array}{l}\text { non-albicans } \\
\text { Candida }\end{array}$ & & & \\
\hline \multirow{3}{*}{$\begin{array}{l}\text { Biofilm } \\
\text { production by } \\
\text { TCP method }\end{array}$} & $\mathrm{M}$ & 1 & 5 & 6 & 0.352 & 0.839 \\
\hline & $\mathrm{S}$ & 12 & 34 & 46 & & \\
\hline & $\mathrm{W}$ & 1 & 2 & 3 & & \\
\hline \multicolumn{2}{|l|}{ Total } & 14 & 41 & 55 & & \\
\hline
\end{tabular}

Note: $P$ value less than 0.05 is significant.

All 55 (100\%) Candida isolates were detected as biofilm producers by Tissue Culture Plate (TCP) method. Out of which, $46(83.63 \%)$ were strong, 6 $(10.9 \%)$ were moderate and $3(5.5 \%)$ were weak biofilm producers.

$12(85.7 \%)$ C. albians and $34(82.9 \%)$ of nonalbicans Candida (NAC) were strong biofilm producers. These 34 (NAC) strong biofilm producers included C. tropicalis 26, C. famata 2, C. haemulonii 2, C. glabrata 1, C. lusitaniae $1, C$. aspergilus 1 and $C$. rugosa 1 .
Candida Biofilm assay (Quantitative)

Quantification of biofilm production of Candida sp. was carried out by XTT reduction assay.

\section{Candida Biofilm detection by XTT reduction assay}

All Candida strains were biofilm producers by this method showing XTT activity above cutoff value, which was 0.025 .

XTT activity observed in Candida strains are depicted in Table 4 and Figure 1.

Table-4: XTT activity of Candida spp

\begin{tabular}{|l|l|l|}
\hline Candida spp. & No of strains & XTT activity range \\
\hline Candida albicans & 14 & $0.09-0.24$ \\
\hline Candida tropicalis (non-albicans) & 29 & $0.06-0.2$ \\
\hline Non albicans Candida (except C. tropicalis) & 12 & $0.06-0.192$ \\
\hline
\end{tabular}

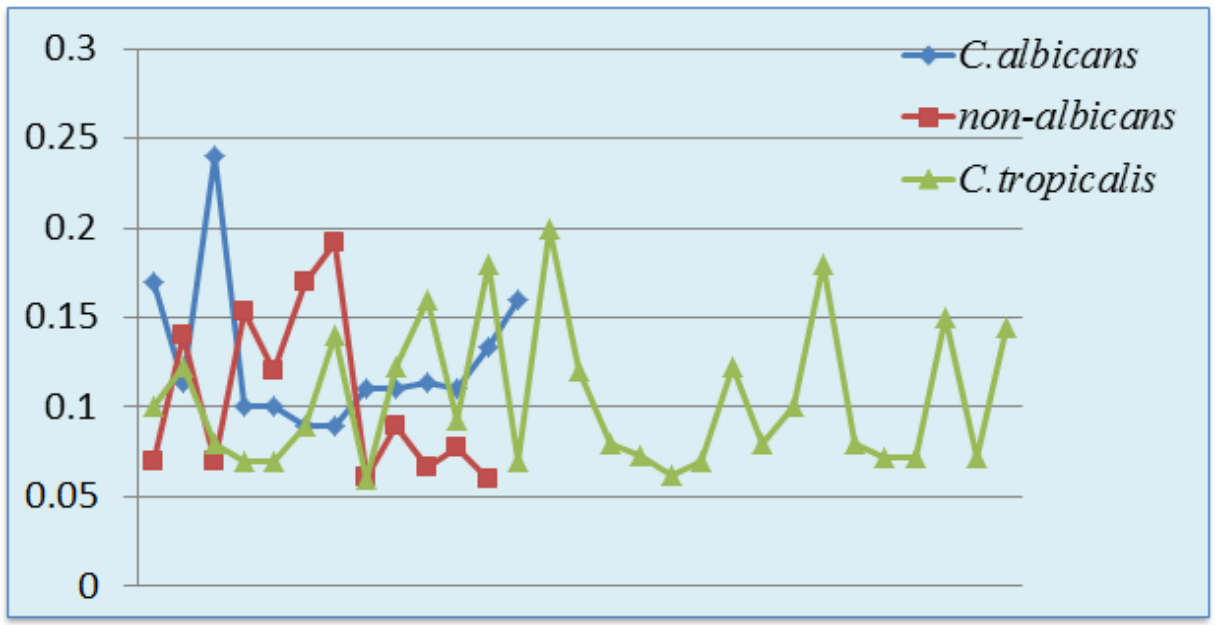

Fig-1: XTT activity of Candida spp

Maximum XTT activity shown by Candida albicans was 0.24 and minimum was 0.09 , while in case of non albicans Candida it was observed that $C$. tropicalis exibits highest XTT activity (0.2) and lowest as 0.06. Among non-albicans Candida group (other than $C$. tropicalis) the maximum value of XTT activity was of $C$. famata $(0.192)$ and minimum was of $C$. aspergilus (0.06).
Weight measurement (Quantification) of Candida biofilm

Quantification of biofilm produced by Candida isolates was performed by dry weight measurement assay and the findings are depicted in table 5 and Figure 2. 
Table-5: DW and WW of biofilm formed by Candida spp

\begin{tabular}{|l|l|l|l|}
\hline Candida spp. & No of strains & DW (mg/disk) & WW (mg/disk) \\
\hline Candida albicans & 14 & $2.3-9.1$ & $2.8-10$ \\
\hline Candida tropicalis (non-albicans) & 29 & $2.2-7.3$ & $2.4-7.5$ \\
\hline Non albicans Candida (except C. tropicalis) & 12 & $2.0-7.1$ & $2.5-7.1$ \\
\hline
\end{tabular}

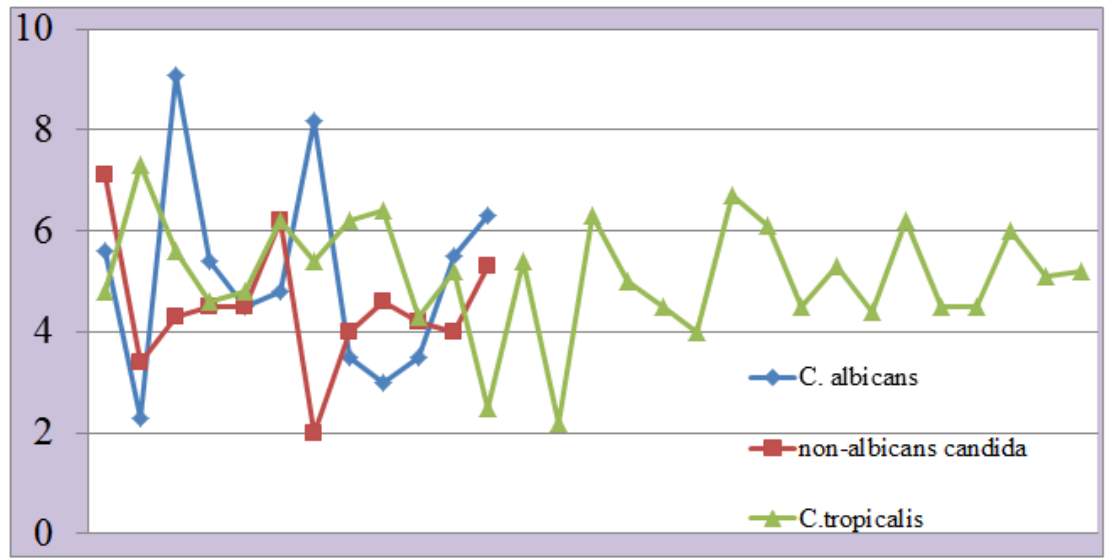

Fig-2: Quantity of biofilm produced by Candida spp. (Dry weight in mg/disk)

Actual quantity of biofilm production is the dry weight (DW) of the biofilm. Quantity of biofilm produced by $C$. albicans ranged between 2.3 to 9.1 $\mathrm{mg} /$ disk. Among non-albicans Candida Candida tropicalis) it was between 2.2 to $7.3 \mathrm{mg} /$ disk whereas non-albicans Candida (except $C$. tropicalis) weight of the biofilm was 2.0 to $7.1 \mathrm{mg} /$ disk.

Table-6: Comparative result of TCP method and dry weight method

\begin{tabular}{|l|l|l|}
\hline Biofilm producing Candida spp. & No. of isolates & Range of dry weight of biofilm in mg/disk \\
\hline Weak & 3 & $2.3-3.4$ \\
\hline Moderate and strong & 52 & $>3.5 \mathrm{mg} / \mathrm{disk}$ \\
\hline
\end{tabular}

Quantity of dry weight (which is the actual amount of biofilm produced by an organism) was below $3.5 \mathrm{mg} / \mathrm{disk}$ for all weak biofilm producers whereas in quantity of dry weight was above $3.5 \mathrm{mg} / \mathrm{disk}$ for moderate and strong biofilm producers. In other words we can say that results of both correlated very well with each other in the present study.

\section{DISCUSSION}

Candida is one of the most frequently encountered opportunistic fungi that cause severe infection in humans because of its virulence factors. The ability of Candida to form biofilms and adhere to host tissues and biomaterial surfaces is an important factor in its pathogenesis. The main characteristics of biofilm are that they are resistant to broad spectrum anti-fungal drugs.

Among 55 Candida isolates from patients having Hospital acquired infections, 14 (25.45\%) were Candida albicans whereas $41(74.55 \%)$ were nonalbicans Candida. Amongst non-albicans Candida, $C$. tropicalis $29(52.72 \%)$ was the most common strain isolated followed by $C$. haemulonii $3(5.45 \%)$, C. famata 3 (5.45\%), C. glabrata 02 (3.64\%), $C$. parapsilosis 01 (1.82\%), C. rugosa 01 (1.82\%), $C$. lusitaniae and C. aspergillus 01 (1.82\%).
The main underlying condition in patients with biofilm producing Candida species was catheterization and prolonged antibiotic therapy. All the 55 isolates tested for biofilm formation were found to be positive for biofilm production by both TM and TCP methods.

Shin et al. [11] observed that $39 \%$ of Candida strains were biofilm producers, of which only $8 \% \mathrm{C}$. albicans and $61 \%$ non-albicans Candida were biofilm producers. Girish Kumar and Menon [12] observed in a study that of the 58 Candida isolates $82.8 \%$ were biofilm producers, which is almost similar to the finding of the present study. Dag et al. [13] study showed that $39.3 \%$ Candida albicans were biofilm producers, which is slight higher in comparison to nonalbicans Candida $37.7 \%$ of which were biofilm producers.

In a study by Mohandas and Bhallal [14] it was detected that of the 111 Candida isolates $73 \%$ were biofilm producers, which is lower than present study. Muni et al. [15] reported biofilm production in $64 \%$ of the 50 Candida isolates by Tube method. According to a study by Nascimento et al. [16] 60.6\% (36.4\% high and $63.6 \%$ weak) were biofilm producers amongst 327 Candida isolates. Among them $43.1 \%$ of $C$. albicans and $75.8 \%$ of non-albicans Candida isolates were found to be positive for biofilm production. They also 
found that $94.6 \%$ of C. tropicalis were biofilm producers. These reported findings are less than present study finding.

Khatri et al. [17] in their study isolated 80 Candida isolates of which $61.25 \%$ isolates were positive biofilm producers by TCP method and TM detected $57.50 \%$ isolates as biofilm producers, which is less than the result of present study.

It was observed in most of the studies that $C$. tropicalis is the commonest isolates, which is similar to the present study. In this study, all of the Candida strains were biofilm producers, which may be due to the fact that all of them are isolated from hospital acquired infections.

\section{XTT Reduction Assay}

In the present study $100 \%$ of Candida isolates were found to be biofilm producers by XTT reduction assay. In a study by Dhale et al. $16.94 \%$ isolates were detected as biofilm positive strains by XTT reduction assay [18], which is in contrast with the present study, but their findings with other methods were also low. Whereas in the present study all isolates were biofilm producers as detected by two different methods. Nweze EI et al. observed that all the Candida isolates were biofilm producers by XTT reduction assay [19]. This is in accordance with the present study.

\section{Quantification of Biofilm}

In the present study all of the Candida isolates showed XTT activity which indicates that all of them are biofilm producers which was well supported by Fluorescent microscopic examination of Silicon elastomer disk. Highest XTT activity was seen in Candida albicans strain whereas least activity was recorded in non- albicans Candida strain (Candida tropicalis) in the present study. Biofilm production measured by dry weight (DW) measurement method were $2 \mathrm{mg} /$ disk to $9.1 \mathrm{mg} /$ disk.

Candida albicans produced maximum amount (DW) of biofilm (9.1mg/disk) and non-albicans Candida produced minimum amount of biofilm quantitatively (Candida Famata, $2.0 \mathrm{mg} /$ disk) in the present study.

Kuhn et al observed similar results in their study that $C$. albicans produces quantitatively more biofilm than other Candida species, as measured by the XTT and DW methods. 3 to $4 \mathrm{mg} /$ disk of biofilm were detected by DW measurement method after 48 hours of incubation. In particular, biofilm DW measurements for $C$. parapsilosis were consistently smaller than those for $C$. albicans. Kuhn et al. also found that the level of XTT activity of biofilm formed by non-invasive isolates was higher than the invasive ones, whereas in case of invasive (DRC) isolates they detected higher DW, which represents the actual biofilm formation [10]. It was also observed by them that biofilm formation ability of $C$. albicans is higher than $S$. cervisiae, as their dry weight were $3.7 \pm 0.001 \mathrm{mg} /$ disk and $1.6 \pm 0.004$ $\mathrm{mg}$ /disk respectively. In the present study only one isolate of Candida parapsilosis was isolated, whose biofilm DW measurement was $3.4 \mathrm{mg} /$ disk less than most of the Candida spp [20, 21].

In the present study dry weight of biofilm detected in weak producers was below $3.5 \mathrm{mg} / \mathrm{disk}$ and in case of strong biofilm producers was above 3.5 $\mathrm{mg} / \mathrm{disk}$. Hence it is concluded that findings of both methods correlated very well.

\section{CONCLUSION}

Biofilm production measured by dry weight (DW) measurement method ranged between $2 \mathrm{mg} / \mathrm{disk}$ to $9.1 \mathrm{mg} /$ disk. Candida albicans produced maximum amount of biofilm $(9.1 \mathrm{mg})$ while $C$. famata produced $2.0 \mathrm{mg} /$ disk.

Quantification of Candida biofilm should be performed and reported as it can help clinicians in deciding dose and duration of antifungal drugs for better and fruitful outcome.

\section{ACKNOWLEDGEMENT}

I am very thankful to the HOD Microbiology department for permission to perform research work.

\section{REFERENCES}

1. Alberth, M., Majoros, L., Kovalecz, G., Borbás, E., Szegedi, I., Márton, I. J., \& Kiss, C. (2006). Significance of oral Candida infections in children with cancer. Pathology \& Oncology Research, 12(4), 237.

2. Marrie, T., \& Costerton, J. W. (1984). Scanning and transmission electron microscopy of in situ bacterial colonization of intravenous and intraarterial catheters. Journal of Clinical Microbiology, 19(5), 687-693.

3. Tchekmedyian, N. S., Newman, K., Moody, M. R., Costerton, J. W., Aisner, J., Schimpff, S. C., \& Reed, W. P. (1986). Case report: special studies of the Hickman catheter of a patient with recurrent bacteremia and candidemia. The American journal of the medical sciences, 291(6), 419-424.

4. Reid, G., Denstedt, J. D., Kang, Y. S., Lam, D., \& Nause, C. (1992). Microbial adhesion and biofilm formation on ureteral stents in vitro and in vivo. The Journal of urology, 148(5), 1592-1594.

5. Elder, M. J., Matheson, M., Stapleton, F., \& Dart, J. K. (1996). Biofilm formation in infectious crystalline keratopathy due to Candida albicans. Cornea, 15(3), 301-304.

6. Chandra, J., \& Mukherjee, P. K. (2015). Candida biofilms: development, architecture, and resistance. Microbiology spectrum, 3(4).

7. Branchini, M. L., Pfaller, M. A., Rhine-Chalberg, J., Frempong, T., \& Isenberg, H. D. (1994). 
Genotypic variation and slime production among blood and catheter isolates of Candida parapsilosis. Journal of clinical microbiology, 32(2), 452-456.

8. Girmenia, C., Martino, P., De Bernardis, F., Gentile, G., Boccanera, M., Monaco, M., ... \& Cassone, A. (1996). Rising incidence of Candida parapsilosis fungemia in patients with hematologic malignancies: clinical aspects, predisposing factors, and differential pathogenicity of the causative strains. Clinical Infectious Diseases, 23(3), 506-514.

9. Pfaller, M. A., Messer, S. A., \& Hollis, R. J. (1995). Variations in DNA subtype, antifungal susceptibility, and slime production among clinical isolates of Candida parapsilosis. Diagnostic microbiology and infectious disease, 21(1), 9-14.

10. Kuhn, D. M., Chandra, J., Mukherjee, P. K., \& Ghannoum, M. A. (2002). Comparison of biofilms formed by Candida albicans and Candida parapsilosis on bioprosthetic surfaces. Infection and immunity, 70(2), 878-888.

11. Shin, J. H., Kee, S. J., Shin, M. G., Kim, S. H., Shin, D. H., Lee, S. K., ... \& Ryang, D. W. (2002). Biofilm production by isolates of Candida species recovered from nonneutropenic patients: comparison of bloodstream isolates with isolates from other sources. Journal of Clinical Microbiology, 40(4), 1244-1248.

12. Girish Kumar, C. P., \& Menon, T. (2006). Biofilm production by clinical isolates of Candida species. Sabouraudia, 44(1), 99-101.

13. Dag, I., Kiraz, N., \& Oz, Y. (2010). Evaluation of different detection methods of biofilm formation in clinical Candida isolates. African Journal of Microbiology Research, 4(24), 2763-2768.

14. Mohandas, V., \& Ballal, M. (2011). Distribution of Candida species in different clinical samples and their virulence: biofilm formation, proteinase and phospholipase production: a study on hospitalized patients in southern India. Journal of global infectious diseases, 3(1), 4.

15. Muni, S., Menon, S., Chande, C., Gohil, A., Chowdhary, A., \& Joshi, A. (2012). Candida biofilm. Bombay Hosp J, 54(1), 19-23.

16. Bruder-Nascimento, A., Camargo, C. H., Mondelli, A. L., Sugizaki, M. F., Sadatsune, T., \& Bagagli, E. (2014). Candida species biofilm and Candida albicans ALS3 polymorphisms in clinical isolates. Brazilian journal of Microbiology, 45(4), 1371-1377.

17. Khatri, S., Sumana, M. N., Mahale, R. P., \& Kishore, A. (2015). Analysing three different screening methods for biofilm formation in clinical isolates of Candida. Journal of Evolution of Medical and Dental Sciences, 4(83), 1451514524.

18. Dhale, R. P., Ghorpade, M. V., \& Dharmadhikari, C. A. (2014). Comparison of various methods used to detect biofilm production of Candida species. Journal of clinical and diagnostic research: JCDR, 8(11), DC18.

19. Nweze, E. I., Ghannoum, A., Chandra, J., Ghannoum, M. A., \& Mukherjee, P. K. (2011). Development of a 96-well catheter-based microdilution method to test antifungal susceptibility of Candida biofilms. Journal of antimicrobial chemotherapy, 67(1), 149-153.

20. Chandra, J. (2001). Mukherjee PK. Hover LL, McCormick T, Ghannoum MA. Biofilm formation by the fungal pathogen Candida albicans: development, architecture, and drug resistance. J Bacteriol, 183, 5385-94.

21. Chandra, J., Mukherjee, P. K., Leidich, S. D., Faddoul, F. F., Hoyer, L. L., Douglas, L. J., \& Ghannoum, M. A. (2001). Antifungal resistance of candidal biofilms formed on denture acrylic in vitro. Journal of dental research, 80(3), 903-908. 